\title{
The temperature distribution in the load-bearing designs using LSTC
}

\author{
Roman Borisevich ${ }^{1 *}$, Aleksey Dragan ${ }^{1}$ \\ ${ }^{1}$ Brest State Technical University, 224017 Moskovskaya 267, Belarus
}

\begin{abstract}
The article discusses wall enclosing structures based on light steel thin-walled structures using mineral wool as a heater. The aim of this work is to determine the most energy-efficient building envelope. For this, two types of steel profile were chosen: thermal profile and thin-walled steel profile. Based on heat engineering calculations, the values of their resistance to heat transfer were obtained. The analysis of the calculations revealed the most energy-efficient design.
\end{abstract}

Key words: steel profile, lightweight steel thin-walled structures, heat transfer resistance, temperature, cold bridge.

\section{Introduction}

Construction is one of the fastest growing industries in the modern world. In almost any country, significant attention is paid to the issues of construction and architecture. One of the problems that has always attracted the attention of specialists is the reduction in the construction time and the cost of building operation. One of the directions for solving this problem is the introduction of the results of modern scientific research into the design and construction of buildings, the use of more advanced building materials that have improved characteristics for reliability and durability. The most important factor affecting the cost of operating a building is its insulation and the cost of heating the finished buildings. Warming is produced around the perimeter of the building, so even in a small area of the building insulation may be hundreds of square meters, which leads to significant costs. In this regard, the task of optimizing architectural and planning decisions of buildings seems quite relevant.

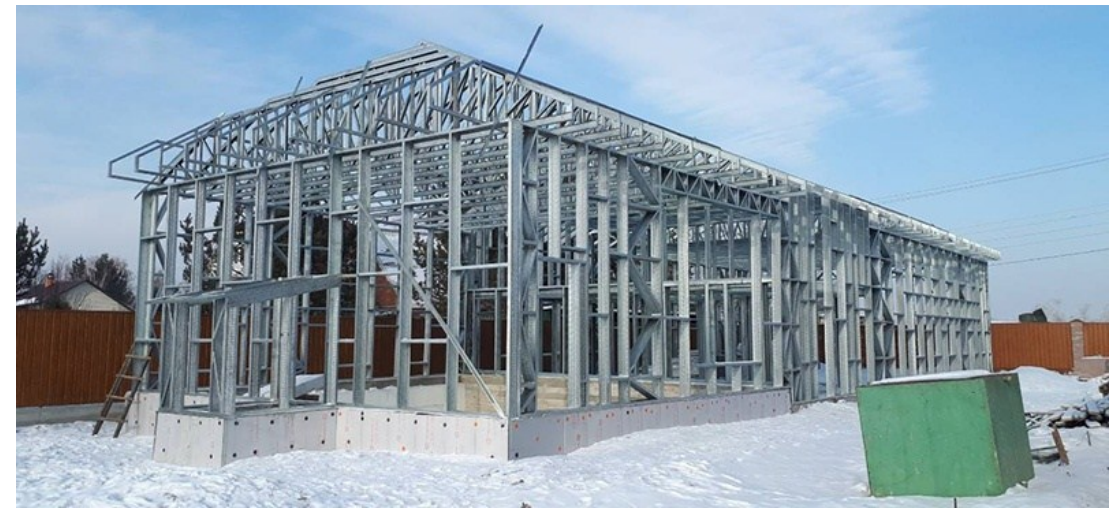

Fig. 1. The supporting frame of a residential building from LSTC

*Corresponding author: borisevich.roma@gmail.org 
Recently, the technology of building using lightweight steel thin-walled structures has become increasingly popular (LSTC) (Fig.1) [1-2]. Steel structures are successfully used both for the construction of industrial facilities, and residential and public buildings. Meanwhile, this material has both advantages and disadvantages. LSTC is a wonderful and promising direction in architecture. After all, metal is one of the most suitable materials for the embodiment of the most incredible ideas. The modern technology of prefabricated construction of LSTC, widely used in the world, makes it possible to significantly save resources and reduce construction time.

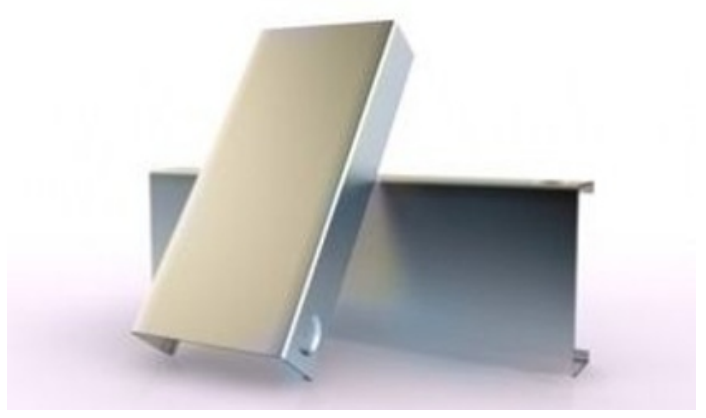

Fig.2. Steel thin-walled structures (STC)

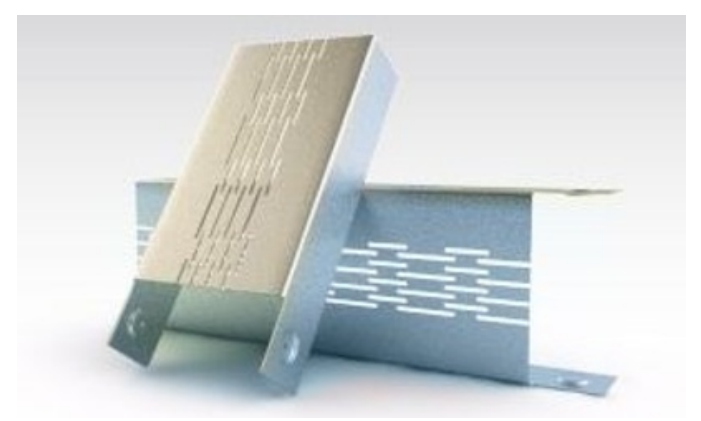

Fig. 3. Thermal profile

Due to the fact that the assembly and installation of structures are performed lower than from prefabricated reinforced concrete structures of factory manufacture. A variety of materials are used to decorate building facades. It can be constructions made of metalplastic, aluminum, siding and corrugated board, special ventilated facade panels (cassettes) or outdoor aquapanel plates. Aquapanel [3] cement-mineral slabs are sheet products consisting of a core based on fine-grained lightweight concrete, all of whose planes (front, back, longitudinal edges), except for the end edges, are reinforced with fiberglass. However, the low heat engineering characteristics of the steel profile (fig. 2) $(\lambda=58$ $\left.\mathrm{W} /\left(\mathrm{m} \cdot{ }^{\circ} \mathrm{C}\right)\right)$, despite all the advantages of LSTC, limited the scope of their mass application in the construction of non-residential buildings and structures.

It should be noted that during the construction of a house from LSTC, a large number of so-called "cold bridges" cannot be avoided.

Thanks to them, the building heat loss increases, which leads not only to a lack of comfort indoors in cold weather travel, but also significantly reduces the service life. In fact, "bridges" are in every building, regardless of building materials. In houses of gas silicate blocks, they are in the seam area. Brick in itself refers to "cold" materials and it is usually insulated with polystyrene foam or mineral wool. In the case of LSTC reduce the influence of "cold joints" using special thermal profiles (fig. 3). 
The development of perforated steel profiles (thermal profiles) allowed us to solve the problem of reducing the thermal conductivity of the metal. According to studies conducted in Finland and Sweden, steel profiles with perforation along the entire length from 4 to 8 rows are most effective from the point of view of energy saving. Their use in building envelopes allows to reduce thermal conductivity along the profile by $70-80 \%$ compared with STC without perforation.

\section{Methods}

Let us calculate the LSTC design shown in fig. 4 as a uniform structure. The calculation was carried out in accordance with [4] by (1).

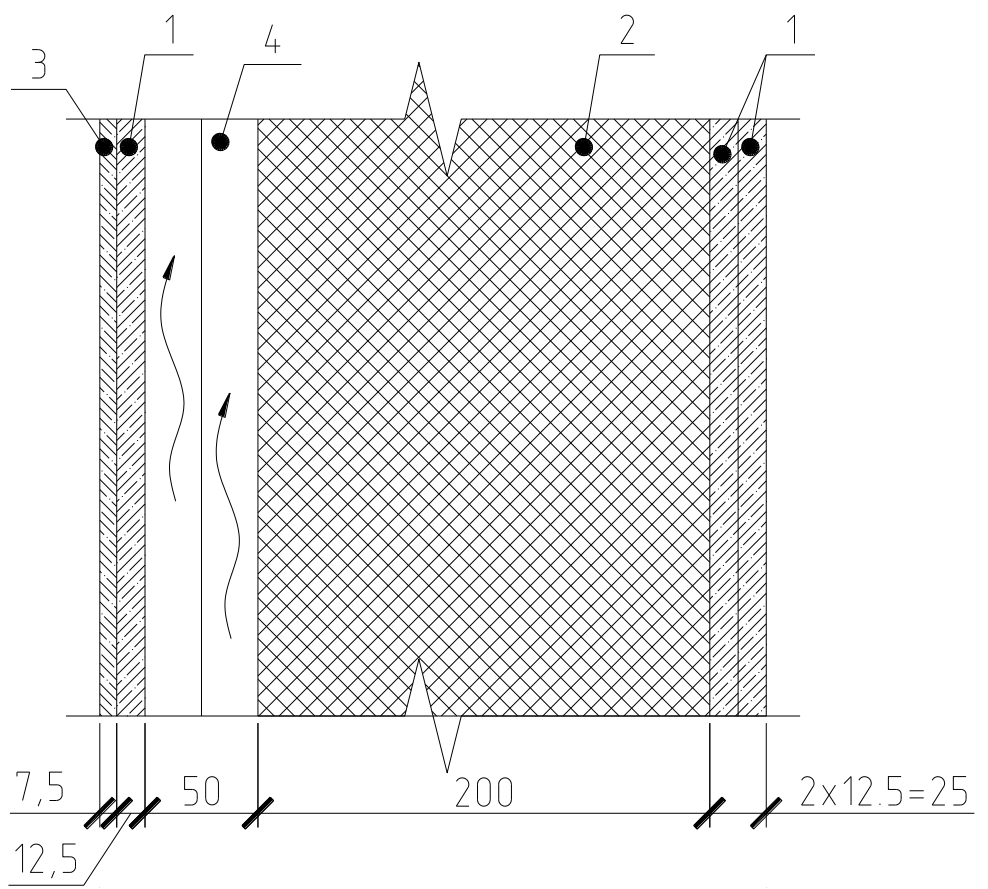

Fig.4. The technical solution of the frame-sheathing external wall includes a steel frame, the outer cladding of Aquapanel Exterior (1 - reinforced cement-mineral slab Aquapanel; 2 - mineral wool ROCKWOOL; 3- finishing layer; 4- air gap)

Table 1. Characteristics of the materials used

\begin{tabular}{|l|c|c|c|}
\hline \multicolumn{1}{|c|}{ Name of material } & $\begin{array}{c}\text { Density, } \\
\mathrm{kg} / \mathrm{m}^{3}\end{array}$ & $\begin{array}{c}\text { Thermal } \\
\text { conductivity, } \\
\mathrm{W} / \mathrm{m}^{\circ}{ }^{\circ} \mathrm{C}\end{array}$ & $\begin{array}{c}\text { Heat } \\
\text { capacity, } \\
\mathrm{J} / \mathrm{kg} \cdot{ }^{\circ} \mathrm{C}\end{array}$ \\
\hline $\begin{array}{l}\text { Reinforced cement-mineral } \\
\text { slab Aquapanel }\end{array}$ & 1100 & 0,32 & 950 \\
\hline $\begin{array}{l}\text { Mineral wool plate } \\
\text { ROCKWOOL }\end{array}$ & 40 & 0,042 & 1050 \\
\hline Steel profile & 7900 & 58 & 434 \\
\hline
\end{tabular}

$$
R=1 / \alpha_{i n}+\delta_{1} / \lambda_{1}+\delta_{2} / \lambda_{2}+1 / \alpha_{o}
$$

$$
R=1 / 8.7+0.025 / 0.32+0.2 / 0.042+1 / 12=5.038 \mathrm{~m}^{2} .{ }^{\circ} \mathrm{C} \mathrm{W}
$$


Since two wall options, in one of which STC is used, and in the other a thermal profile, are calculated without taking into account the profile passing through the thickness of the heat-insulating layer, we get the same value of thermal resistance in both cases.

To take into account the reduction in thermal resistance in the presence of profiles, we determine the required heat transfer resistance on the inner surface of the wall using the COMSOL [5] software package. Conditionally accept wall $1.2 \times 1 \mathrm{~m}$. fragment [6-7], since the frame consists of walls LSTC rack profiles set at $600 \mathrm{~mm}$. Let us identical for the two variants of the boundary values of temperature and heat transfer coefficients for the inner and outer surfaces (table 2), as well as the thickness and structure (fig. 4) and the proposed materials (table 1).

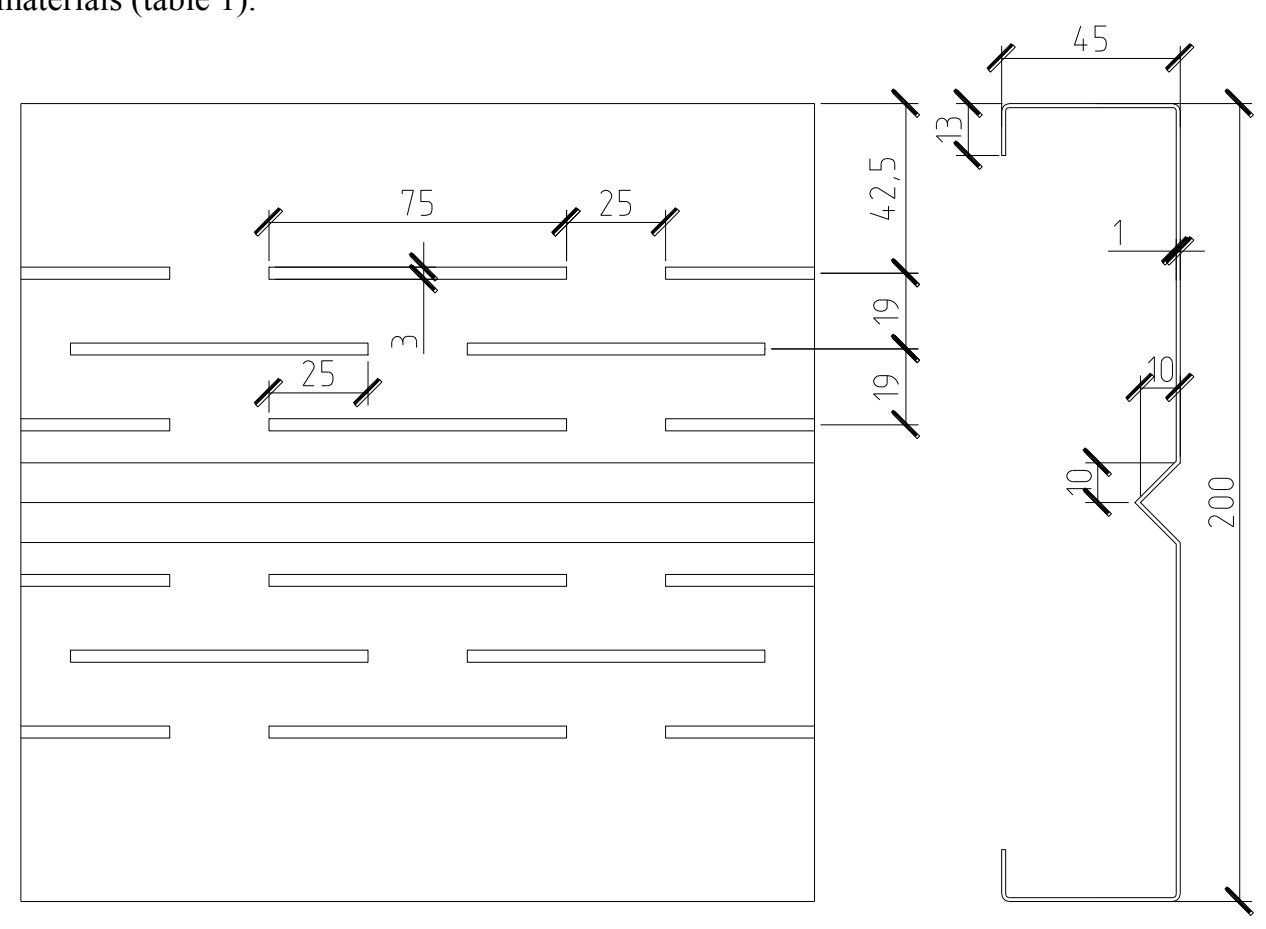

Fig.5. Thermal profile geometrical characteristics

Required thermal resistance, $\mathrm{m}^{2} \cdot{ }^{\circ} \mathrm{C} / \mathrm{W}$, determined by the formula:

$$
R=n\left(t_{i}-t_{o}\right) /\left(\alpha_{i n} \Delta t_{i n}\right)
$$

$t_{\mathrm{i}}$ - calculated temperature of indoor air, ${ }^{\circ} \mathrm{C}$, taken in accordance with the process design;

$t_{\mathrm{o}}$ - calculated winter outdoor temperature, ${ }^{\circ} \mathrm{C}$, taken according to table 4.3 [4], taking into account the thermal inertia of the building envelope D (except for filling openings) according to table 5.2 [4];

$n$ - coefficient taking into account the position of the outer surface of the building with respect to the outside air, taken according to table 5.4 [4];

$\alpha_{\text {in }}-$ heat transfer coefficient of the inner surface of the building envelope, $\mathrm{W} /\left(\mathrm{m}^{2} \cdot{ }^{\circ} \mathrm{C}\right)$, taken according to table 5.5[4];

$\Delta t_{\text {in }}$ - the calculated difference between the temperature of indoor air and the temperature of the inner surface of the enclosing structure, ${ }^{\circ} \mathrm{C}$, taken according to table $5.5[4]$. 


\section{Results and Discussion}

Table 2. Result

\begin{tabular}{|l|l|l|l|l|l|l|l|c|}
\hline Profile & $\mathrm{n}$ & $\begin{array}{l}\alpha_{\text {in, }} \\
\mathrm{W} /\left(\mathrm{m}^{2} \cdot{ }^{\circ} \mathrm{C}\right)\end{array}$ & $\begin{array}{l}\mathrm{t}_{\text {in }} / \\
\mathrm{t}_{\mathrm{o}},{ }^{\circ} \mathrm{C}\end{array}$ & $\begin{array}{l}\mathrm{t}_{\text {in }}-\mathrm{t}_{\mathrm{o}}, \\
{ }^{\circ} \mathrm{C}\end{array}$ & $\begin{array}{l}\Delta \mathrm{t}_{\text {in.s. }}, \\
{ }^{\circ} \mathrm{C}\end{array}$ & $\begin{array}{l}\Delta \mathrm{t}_{\text {in, }}, \\
{ }^{\circ} \mathrm{C}\end{array}$ & $\begin{array}{l}\mathrm{q}, \\
\mathrm{W} / \mathrm{m}^{2}\end{array}$ & $\begin{array}{l}\mathrm{R}, \\
\mathrm{m}^{2} \cdot{ }^{\circ} \mathrm{C} / \mathrm{W}\end{array}$ \\
\hline STC & \multirow{2}{*}{1} & 8,7 & $\begin{array}{l}+18 / \\
-21\end{array}$ & 39 & 15,96 & 2.04 & 17,79 & 2.19 \\
\cline { 1 - 5 } $\begin{array}{l}\text { Thermal } \\
\text { profile }\end{array}$ & & & $\begin{array}{l}+18 / \\
-21\end{array}$ & 39 & 16,69 & 1.31 & 11,44 & 3.41 \\
\hline
\end{tabular}

a
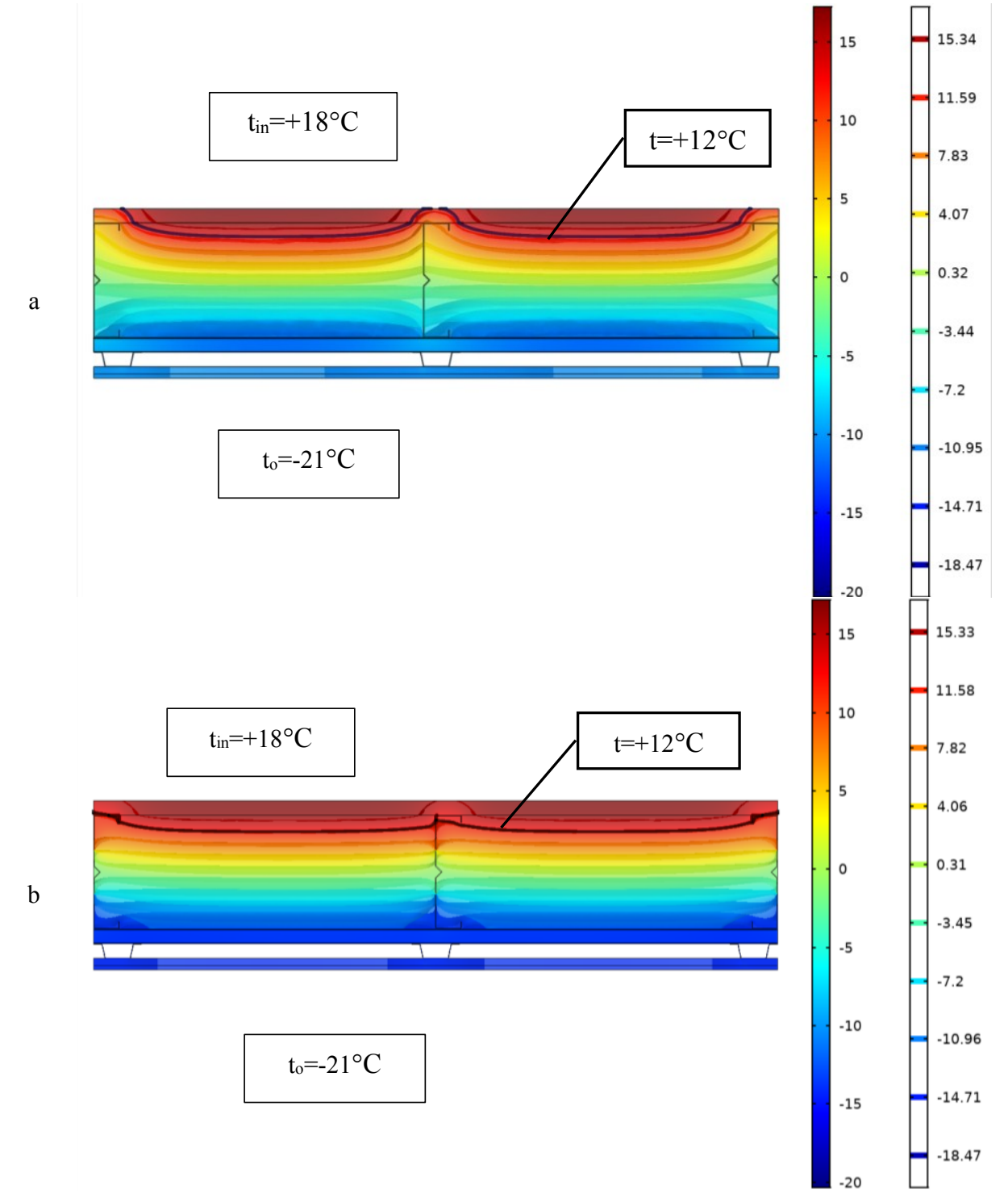

Fig.6. Distribution on a heater temperature: (a) - STC, (b) - Thermal profile

The result of calculation obtained data allow to conclude that the perforations in the more smoothly thermal profiles help distribute the heat loss of insulant (fig. 6b) and reduce the heat losses in the profile (fig. 7). At the same time, in Figure 6a, it is seen that at the 
wall using STC, the calculated difference between the temperature of the internal air and the temperature of the internal surface is more than $6^{\circ} \mathrm{C}$, which causes freezing. Also, according to the results STC profile when adopted to the wall thickness is not appropriate, since the thermal resistance of less standard, which is $3,2 \mathrm{~m}^{2} \cdot{ }^{\circ} \mathrm{C} / \mathrm{W}$.
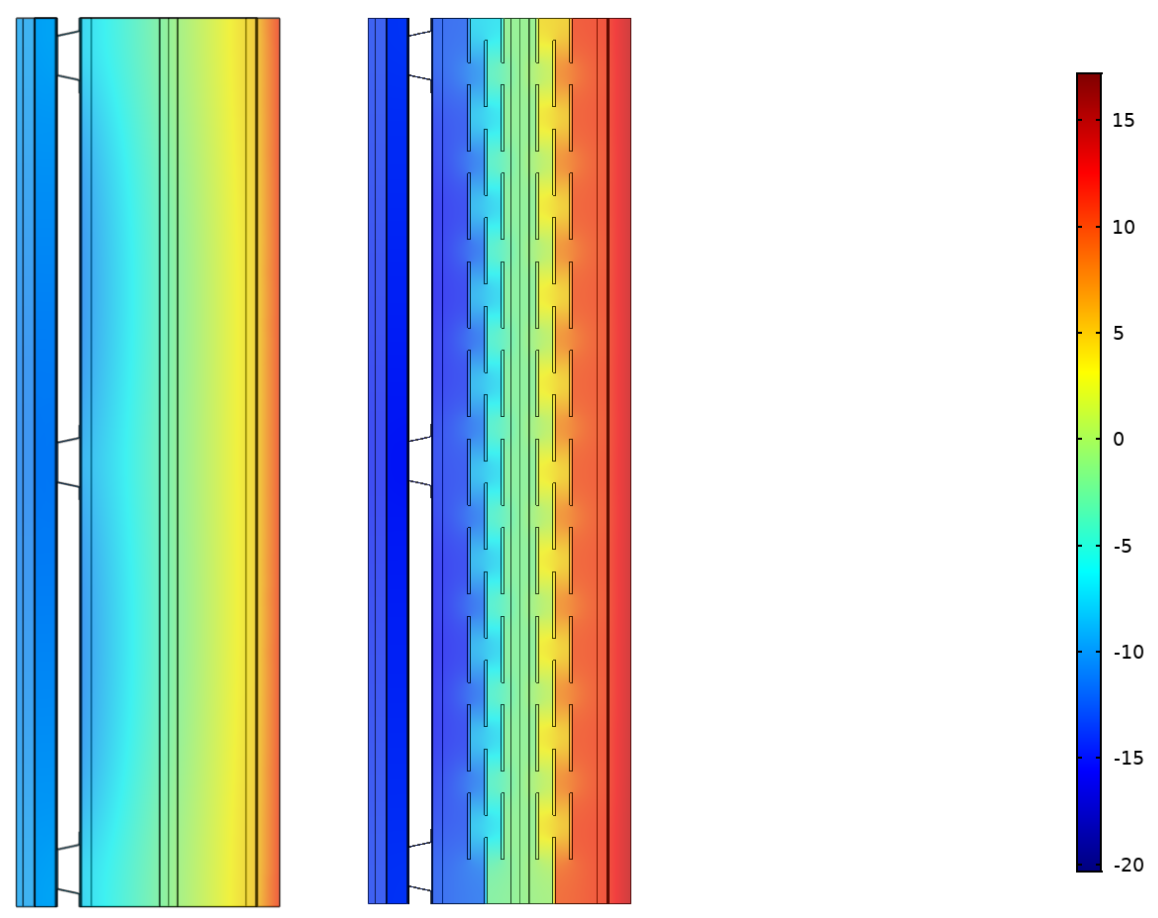

Fig. 7. Distribution of temperature profile (left - STC, right- thermal profile)

\section{Conclusion}

In this work, we calculated the specific heat loss for external frame-sheathing walls using a framework made of LSTC.Structures with a thermo-profile passing through the insulation were studied. A great influence on the structural design characteristics of perforation of a thermal profile is noted. Conventional profiles in such structures are practically unsuitable for use due to large heat losses. To further improve the characteristics of the structures under consideration, it is necessary to increase the perforation of the thermal profile and change their shape, or provide for an increase in the thermal insulation layer.

\section{References}

1. M. Veljkovich, B. Johansson, Thin -Wall Str 44, pp. 1272-1279 (2006)

2. B. Johansson, Magazine of Civil Engineering 6, pp. 2-3 (2009)

3. The album of technical solutions "KNAUF AQUAPANEL® External wall. External load-bearing frame-sheathing walls with a frame made of steel thin-walled coldformed galvanized profiles using KNAUF materials "(2018)

4. TCP 45-2.04-43-2006. Construction heat engineering (Minsk, 2006) 
5. R.W. Pryor, Multiphysics modeling using COMSOL: a first principle approach (Jones \& Bartlett Publishers, Inc, 2011)

6. P 1.04.115.13. Recommendations for calculating the reduced heat transfer resistance of building envelopes and calculating heat loss through the enclosure (Minsk, 2013)

7. GOST P 58774-2019. The external walls are frame-sheathed self-supporting and non-bearing with a frame made of cold-rolled steel galvanized profiles. General specifications. (Moscow, Standardinform, 2020.) 